\title{
THE DEVELOPMENT OF SUSTAINABLE DESIGN DECISION TOOL FOR PUBLIC BUILDINGS IN INDONESIA
}

\author{
Hamdi Akmal Lubis \\ Civil Engineering Dept, Fac. of Engineering, University of Malikussaleh \\ hamdi_akmal@yahoo.com
}

\begin{abstract}
Sustainable building has become a catchphrase in many countries. Issue on sustainability has attracted researchers from industry and academia in recent years, and the number is still growing. Despite different definitions of sustainable building, quality improvement of the environment, economy, and social well-being are always seen as three major affecting factors. As part of a larger future research framework, the result of this preliminary research work suggested that a low-cost design decision tool is worth researching. This paper will first, review some of assessment tools currently available today and discuss a new research direction for optimizing the application of those three factors into project appraisal process by utilizing LifeCycle Costing (LCC) analysis and second, outline research methodology for the development of a decision tool in selecting sustainable options for public buildings design in Indonesia.
\end{abstract}

Keywords: Sustainable building, life-cycle costing, decision support tools, construction investment

\section{Introduction}

Infrastructure planning in Indonesia has not been concerned with being wholly sustainable. Building sectors as like many infrastructures such as roads, dams, power plants, transportations, etc in Indonesia has a great potential emission reduction (Naning, et. al., 2010). The building sector in Indonesia could reduce its emissions through six areas. These includes: Alternative water heating replacements, efficient lighting replacements, efficient electronics replacements, efficient appliances replacements, retrofit building packages, and new building packages (Anonymous, 2010). Statistics showed that during 1970 to 2004, average annual growth of final energy consumption in Indonesia was about $8.4 \%$. The building sector is the third largest in terms of energy consumption, following the industrial and transportation sectors. In 2004, the building sector accounted for $27 \%$ of total final energy consumption (with industry at $39 \%$, and transportation at $33 \%$ ), and is expected to rise to $39 \%$ by 2030 (Anonymous, 2006).

The challenge facing by Indonesia and other developing countries is that green and sustainable assets in its regions may carry considerably higher purchasing price than their less sustainable substitutes. Current development shows that sustainability has not yet an integral part of decision making and business practice. The general perception is that the introduction of sustainable in

The Development of Sustainable Design Decision Tool For Public Buildings 
construction practices will increase costs and reduce profit. The construction industry in developing countries has lack of resources to invest in the technological changes required for the application of sustainable concept.

Presently, the concept of sustainable in construction governs three main pillars: environmental protection, social well-being and economic prosperity. Environmental protection can be in the form of using more recycled materials, and efficient use of energy and mineral resources (Addis and Talbot, 2001). Social well-being concerns with the benefits of the workers and the occupants, such as, satisfaction, safety and comfort (Lombardi, 2001) and human contributions: skills, health, knowledge and motivation (Parkin, 2000). Finally, the economic sustainability is concerned with the micro and macro-economic benefit. Microeconomic focuses on the factors or activities which could lead to monetary gains from the construction while macro-economic relates to the advantages gained by the public and government from the project success. The concept of sustainability in building has initially focused on issues of limited resources especially energy, and on how to reduce impacts on the natural environment with emphasis on technical issues such as materials, building components, construction technologies and energy related design concepts.

In simple term, sustainably designed building can be defined as those buildings that have minimum adverse impacts on the built and natural environment, in terms of the buildings themselves, their immediate surroundings and the broader regional and global setting (Anonymous, 2012). Sustainably designed building strives for integral quality (including economic, social and environmental performance) in a very broad way. Thus, the rational use of natural resources and appropriate management of the building stock will contribute to saving scarce resources, reducing energy consumption, and improving environmental quality.

\section{Review of sustainable assessment tools}

In macro level, several developed countries have set up the national building rating and assessment tool to meet their sustainability objectives such as LEED (US), BREEAM (UK), GBTool (Canada), CASBEE (Japan), Green Star (Aus), DGNB (Germany), Green Office and Green Home schemes (NZ). While there are many similarities between these tools, the various methods of assessment and scoring are different to some degree. The differences generally reflect variations in the market to which they cater, the stage of the building process to which they apply, the environmental issues they address, and the purpose for which they have been designed (Hargreaves, 2005).

Similar initiative has also been taken by Indonesian Green Building Council (IGBC) in 2010. The rating tool, Greenship has been developed in cooperation with related experts, industries, government, and academics in Indonesia. Greenship is used to evaluate and determine green achievements, prior to green building certification. In the tool, the following criteria are valued: Appropriate site development (16 points), energy efficiency and conservation (36 points), water conservation (20 points), material resource and cycle (12 points), indoor 
health and comfort (20 points), and building environment management (13 points). Depending on the sum of the point values achieved, the building is certified accordingly (Anonymous, 2010).

Although various rating and assessment tools are useful for defining the concept of sustainability, however the real determinant of the success of any national goal remains the translation of strategic policy initiatives to concrete design guidelines and actions at the micro level. These include an emphasis on performance outcomes such as, the need for regional variations, the need for variations for different building types, the trend toward more requirements rather than point-based alternatives, and more focus on actual building performance during occupancy and operation. Such translations at the micro level (Newel, 1982) are required to enable designers to assess the impacts of their design decisions as they contribute to achieving the National sustainability goals.

Most of the environmental building assessment tools described above cover the building sector and based on some form of life-cycle assessment database (Tucker, et., al., 2006). Tools are basically divided in two categories: assessment and rating tools. Assessment tools provide quantitative performance indicators for design alternatives whilst rating tools determine the performance level of a building in stars. As environmental issues become more urgent, more comprehensive building assessment methods are required to assess building performance across a broader range of environmental considerations (Cooper, 1999; Kohler, 1999). An environmental building assessment method reflects the significance of the concept of sustainability in the context of building design and subsequent construction work on site. The primary role of an environmental building assessment method is to provide a comprehensive assessment of the environmental characteristics of a building (Cole, 1999) using a common and verifiable set of criteria and targets for building owners and designers to achieve higher environmental standards. It also enhances the environmental awareness of building practices and lays down the fundamental direction for the building sector to move towards environmental protection and achieving the goal of sustainability of any nation.

Many literatures suggest that sustainability should be seen in a holistic way. Since every region is unique, the need to address sustainability assessment at the project or micro level has been discussed and highlighted in literatures (Odysseus, 2003; Zhou and Lowe, 2003). In achieving sustainable building design, focus on the total life-cycle cost is necessary to ensure that decisions made in every project phase contribute to the sustainability of the project. Sustainable construction projects usually call for a higher initial investment with lower operational costs; making investment decisions based on life cycle costs or cost-of-ownership principles is therefore important (Bull, 1993). Life-cycle costing (LCC) is used to make founded decisions in comparing alternative building designs in relation to future costs over the life cycle (Cole and Sterner, 2000; de Ridder, 2008). The method enables operational cost (i.e. cost-of-ownership) benefits to be evaluated against initial investment increases (Cole and Sterner, 2000). 
LCC was originally designed for procurement purposes in the U.S. Department of Defence (White and Ostwald, 1976) and is still used most commonly in the military sector as well as in the construction industry (Woodward, 1997). Public sector has been a relevant promoter for life cycle cost calculations (Woodward, 1997). However, there are relatively few articles written about the application of LCC in public project appraisal. In a Finnish study only 5 $\%$ of large industrial companies had used life cycle costing (Hyvönen, 2003). In a Swedish building industry study $66 \%$ of private companies used life cycle costing to assist on decision making (Sterner, 2000) and in a U.S. study $40 \%$ of city administrations used life cycle cost analysis when assessing their building projects (Ardit and Messiha, 1999).

The importance of LCC in building construction stems from the actual distribution of costs incurred over the life of a project. Buildings are typically long term investments, such as schools, hospitals, etc and the valuation models must account for all costs and benefits throughout the length of ownership. Initial capital cost of a typical office building accounts for only $2-10 \%$ of costs incurred over the life of the structure, while the remaining $90-98 \%$ of costs are realized in operation, maintenance, financing, and staffing (Anonymous, 1996). LCC analysis is best suited for evaluating alternative construction applications where quality and long-term value are primary goals. Because city, state, and federal projects represent the public interest, the government sector has been most active in developing standards and initiating mandates for the use of LCC for procurement. Many public construction projects require LCC analysis for substantial infrastructure improvements (highways, bridges, and wastewater treatment facilities), aimed toward durability and longevity, as well as buildings, where energy and water efficiency are paramount (Anonymous, 2002).

Since green building initiatives are predicated on the understanding that benefits accrue over the life of the project, LCC applied to development of sustainable design is appropriate when choosing to build green. The necessity of implementing LCC analysis early in the project appraisal and using multidisciplinary teams parallels the green building philosophy of front loading or designing for end use/ least cost objectives. Any project appraisal requires three basic aspects to be examined. First, the project should comply with national, regional and local land use planning guidance and policy. Second, the proposed principle and design for the project should be appropriate for meeting its stated objectives. This should take into account potential alternative means to meet the objectives, and also other locations and engineering designs (Bartlett and Howard, 2000).

\section{Perceived challenges in the developing regions}

Indonesia is lag behind from neighborhood countries like Malaysia, Singapore, and Australia which already established its national rating system few years ago (Green Building Index of Malaysia, Green Mark of Singapore, and GreenStar of Australia).

As devoted in the literatures, sustainable design criteria are different from country to country or even region to region in the same country. Indonesia is a 
large country and poses varying degree of climate and geographical conditions. Inefficient energy use from the building (sick building) and the excessive use of natural resources (timber, soil, etc) is mostly occurred in the developing regions (sample of developing regions are Aceh, Kalimantan and Papua). Therefore, research on sustainable design in every region with some huge climate differences among them is necessary to provide valuable input and contribution to the national goals of sustainable infrastructure development. In addition, for regions which have limited public spending on its infrastructure development, the contribution made from this research can be realized and promote the paradigm shift in how new buildings are designed.

The new direction of research will concentrated on the application of LCC in the less developed region in Indonesia. The intention is not to modify or replace commercial off-the shelf LCC package currently available, rather it will research the possibility of developing simple and practical use of LCC analysis using technology or IT tool available in the local or regional level. More too often, the sophisticated LCC tools are expensive or need an expert consultation. This research however specially designed to fill the research gap on designing sustainable building with limited public funding while considering local values and culture.

The general hypothesis is that less developed regions in Indonesia consume significant amount of natural resource for its infrastructure project. Hence, to achieve better sustainability, an LCC analysis tool based on local or regional characteristics applied during project appraisal could make significant improvement in the selection of design alternatives.

\section{Research methodology}

The main research objective is to develop a low-cost sustainable design decision tool for public building project. The study will focus on incorporating LCC analysis during project appraisal with aim of assisting decision makers to select the best value for money towards the development of sustainable building. A tool will be designed to allow LCC analysis using database specifically build upon a foundation of knowledge regarding material specification, service-life of components, and other significant cost items according to the local and regional context. The tool should be able to use as basis of evaluating different alternatives effect on life-cycle cost and environmental impact during project appraisal and design brief.

Based on current studies, the methodology to develop a sustainable design decision tool in new public building in Indonesia is outlined as follows:

1. Design a questionnaire survey to investigate the sustainable building design criteria followed by interviews with design professionals, local public authorities and Indonesian Green Building Council (IGBC). Consultation with IGBC is deemed necessary where the national building assessment tool called the Greenship has been established to assess the sustainability for new and existing building. 
The second part of the questionnaire will be used to collect information on the extent use of LCC by clients in public sector. This part of questionnaire survey will be designed to investigate current practice of project appraisal techniques. Findings from this stage will be analyzed using descriptive statistic technique.

2. Develop a project appraisal model integrating LCC analysis. The uncertainty associated with the selection of alternative will be analyzed using deterministic techniques such as sensitivity analysis. A series of test case will be conducted to ensure the workability of the tool.

Sensitivity analysis plays a fundamental role in decision-making because it determines the effects of a change in a decision parameter on system performance. Sensitivity analysis is the study of how the variation in the output of a model can be apportioned, qualitatively or quantitatively, to different sources of variation, and how the given model depends upon the information fed into it (Saltelli, et., al., 2000). It is a technique for systematically changing variables in a model to determine the effects of such changes (Saltelli, et., al., 2008).The parameter can be, among others, an assumption in the study (e.g. the choice to include or exclude infrastructure data) or a data source (e.g. different databases (Rypdal and Flugsrud, 2001)). Hence, this part determines the effects of a change in a decision parameter on system performance in order to see and predict how varying projections of variables affect environmental impacts.

In any budgeting process there are always variables that are uncertain. Future tax rates, interest rates, inflation rates, headcount, operating expenses and other variables may not be known with great precision. In more general terms uncertainty and sensitivity analysis investigate the robustness of a study when the study includes some form of statistical modeling. Sensitivity analysis can be useful to computer modelers for a range of purposes, (Campolongo, et., al., 2007) including:

- Support decision making or the development of recommendations for decision makers (e.g. testing the robustness of a result);

- Enhancing communication from modelers to decision makers (e.g. by making recommendations more credible, understandable, compelling or persuasive);

- Increased understanding or quantification of the system (e.g. understanding relationships between input and output variables); and model development (e.g. searching for errors in the model).

\section{Discussions}

Findings from this preliminary research work suggested that the development of sustainable building design tool cannot blindly follow similar tools created in other countries because of the different nature of geographical area. There is no one-size-fits-all solution to design a sustainable building. A decision tool for designing sustainable building shall be seen holistically. For example, a more comprehensive study need to be performed in addressing classical challenges of developing reliable computer model, such as different platform system, compatibility of hardware and software system, etc. 
Results from the review of literatures conclude that a key aspect of moving toward more performance-based outcomes in sustainable design is the use of LCC to determine the embodied environmental effects of materials, rather than relying on singular material properties such as recycled content or distances traveled after the point of manufacture. The assessment of environmental effect is most efficient during the appraisal stage of a project to minimize environmental damage, maximize the return to natural resources and reduce remedial costs (Lowton, 1997; Crookes and de Wit, 2002). The need to integrate LCC into sustainable project appraisal is important to support design decision by practitioners and local authority. While there has been considerable research on LCC in the developed countries, there are little data on what LCC approaches and applications are being used and the extent to which they are taken up early at project appraisal stage. Therefore, by incorporating LCC earlier during project appraisal, local authorities are given the opportunity to demonstrate that the best value for money in developing green and sustainable buildings.

Several focuses of study can also be undertaken in the future at a certain level depends on own area of interest, such as: a) identifying the fundamental criteria to be considered in order to ensure that the development conforms to sustainable practice, b) investigating the environmental aspects related to buildings e.g., energy use, use of material, indoor air quality, or, c) developing local or regional database consisting of life-cycle data of common material and building components.

\section{Acknowledgement}

The Author would like to thank Prof. Dr. Ing Kunibert Lennerts, Karlsruhe Institute of Technology, Germany, and anonymous referees for valuable comments on this article. The Author also thanks Mr. Fasdarsyah, ST, MT, Head of Civil Eng. Dept., University of Malikusssaleh, Aceh - Indonesia for his great support. Upmost appreciation is credited to DAAD-Aceh Scholarship of Excellence Program for supporting future research works on this topic.

\section{References}

1. Addis, B., and Talbot, R, 2001, Sustainable Construction Procurement: A Guide To Delivering Environmentally Responsible Projects, CIRIA C571, London: CIRIA.

2. Anonymous, 2012, http://www1.oecd.org/env/efficiency/susbuild.htm, Increasing resource efficiency.

3. Anonymous, 2010, Indonesia's Greenhouse Gas Abatement Cost Curve, http://www.dnpi.go.id/report/DNPI-Media-Kit/reports/indonesiaghg_abatement_cost_curve/Indonesia_ghg_cost_curve_english.pdf

4. Anonymous, 2010, Indonesian Green Building Council, http://www.gbcindonesia.org/

5. Anonymous, 2006, Asia/World Energy Outlook 2006, http://www.keei.re.kr/keei/main_eng.html

6. Anonymous, 2002, U.S. General Services Administration, http://www.gsa.gov/portal/content/104462 
7. Anonymous, 1996, Sustainable Building Technical Manual, http://www.smartcommunities.ncat.org/pdf/sbtpdf

8. Ardit, D., Messiha H.M., 1999, Life Cycle Cost Analysis (LCCA) in municipal organizations, Journal of Infrastructure Systems, Vol. 5, No. 1, pp. $1-10$.

9. Bartlett, E., Howard, N, 2000, Informing the decision makers on the cost and value of green building, Building Research and Information, vol. 28, no. 5/6, pp. $315-324$.

10. Bull, J.W, 1993, Life cycle costing for construction London; New York, Black Academic \& Professional.

11. Campolongo, F., J. Cariboni, and A. Saltelli, 2007, An effective screening design for sensitivity analysis of large models, Environmental Modelling and Software, 22, 1509-1518.

12. Cole, R.J., E. Sterner, 2000, Reconciling theory and practice of life-cycle costing, Building Research \& Information, Vol. 28, pp. 368-375.

13. Cole, R.J., 1999, Building environmental assessment methods: clarifying intentions, Building Research and Information, Vol. 27 (4/5), pp. 230-246.

14. Cooper, I., 1999, Which focus for building assessment methodsenvironmental performance or sustainability?, Building Research and Information, Vol. 27 (4/5), pp. 321-331.

15. Crookes, D., de Wit, M., 2002, Environmental economic valuation and its application in environmental assessment: an evaluation of the status quo with reference to South Africa, Impact Assessment and Project Appraisal, June, pp. 127-134.

16. De Ridder, H.A.J, 2008, Living Building Environment for Sustainable Development in a fast Changing World, In Delft science in design conference proceedings, 4 April 2007, Amsterdam, IOS Press.

17. Hargreaves, R, 2005, Compendium and Evaluation of Building Environmental Impact Schemes being used in Australasia, BRANZ SR 135. Judgeford, Wellington.

18. Hyvönen, T., 2003, Management accounting and information systems: ERP versus BoB, European Accounting Review, Vol. 12, No. 1, pp. 155-173.

19. Kohler, N., 1999, The relevance of green building challenge: an observer's perspective, Building Research and Information, Vol. 27 (4/5), pp. 309-320.

20. Lombardi, P., L, 2001, Responsibilities towards the coming generations: Forming a new creed, Urban Design Studies, Vol. 7, pp. 89 - 102.

21. Lowton, R.M., 1997, Construction and the Natural Environment, Butterworth Heinemann, Oxford.

22. Naning, S. A. A., Prasetyoadi, Savitra P, 2010, Towards Indonesia's Sustainable Future through Sustainable Building and Construction, in Sustainable Buildings South-East Asia Conference. Kuala Lumpur, Malaysia.

23. Newel, A., 1982, The knowledge level, Artificial Intelligence, Vol. 18, No. 1, pp 87-127

24. Odysseus M, 2003, Using Sustainability Related Criteria in Construction Support Systems, Proceedings of 2nd, International conference on Construction Innovation and Sustainability in the 21st Century, Hong Kong, 12-15 December 2003. 
25. Parkin, S, 2000, Sustainable Development: the concept and the practical challenge, Proceedings of the Institution of Civil Engineers: Civil Engineering, Vol. 138(special issue 2), pp. 3 - 8.

26. Rypdal. K., Flugsrud. K, 2001, Sensitivity analysis as a tool for systematic reductions in greenhouse gas inventory uncertainties, Environmental Science \& Policy 4. 117-135.

27. Saltelli. A., Chan. K., and Scott. E.M, 2000, Sensitivity Analysis. Wiley. England.

28. Saltelli, A., Ratto, M., Andres, T., Campolongo, F., Cariboni, J., Gatelli, D. Saisana, M., and Tarantola, S., 2008, Global Sensitivity Analysis. The Primer, John Wiley \& Sons

29. Seo, S., Tucker, S., Ambrose, M., Mitchell, P., Wang, C.H., 2006, Technical Evaluation of Environmental Assessment Rating Tools, Research and Development Corporation, Project No. PN05.1019.

30. Sterner, E., 2000, Life-cycle costing and its use in the Swedish building sector, Building Research \& Information, Vol. 28, No. 5, pp. 387-393.

31. White, G.E., Ostwald, P.F., 1976, The life cycle cost of an item is the sum of all funds expended in support of the item from its conception and fabrication through its operation to the end of its useful life, Management Accounting, Vol. 57, No. 7, pp. 39-42.

32. Woodward, D., 1997, Life cycle costing - theory, information acquisition and application, International Journal of Project Management, Vol. 15, No. 6, pp. 335-344.

33. Zhou L, Lowe D. J, 2003, Economic Principles of Sustainable Construction, in Proceedings of 2 nd, International conference on Construction Innovation and Sustainability in the 21st Century, Hong Kong, 12-15 December 2003. 